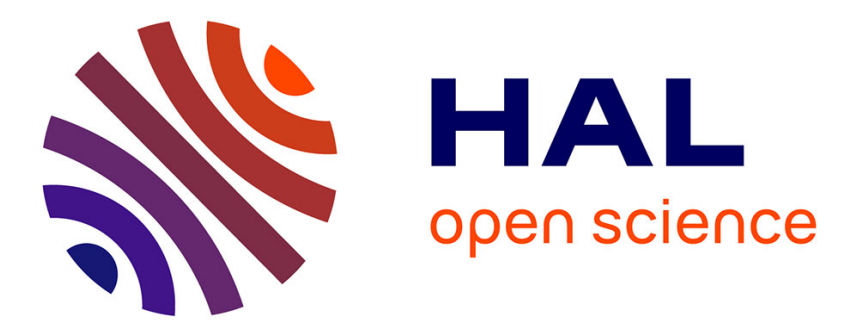

\title{
The evolution of music: One trait, many ultimate-level explanations
}

\author{
Edgar Dubourg, Jean-Baptiste André, Nicolas Baumard
}

\section{To cite this version:}

Edgar Dubourg, Jean-Baptiste André, Nicolas Baumard. The evolution of music: One trait, many ultimate-level explanations. Behavioral and Brain Sciences, 2021, 44, pp.e98. 10.1017/S0140525X20001156. ijn_03472576

\section{HAL Id: ijn_03472576 \\ https://hal.science/ijn_03472576}

Submitted on 9 Dec 2021

HAL is a multi-disciplinary open access archive for the deposit and dissemination of scientific research documents, whether they are published or not. The documents may come from teaching and research institutions in France or abroad, or from public or private research centers.
L'archive ouverte pluridisciplinaire HAL, est destinée au dépôt et à la diffusion de documents scientifiques de niveau recherche, publiés ou non, émanant des établissements d'enseignement et de recherche français ou étrangers, des laboratoires publics ou privés. 


\title{
Commentary for Mehr et al.: Origins of music in credible signaling
}

\author{
Word counts: \\ Abstract: 40 words \\ Main text: 1004 words \\ References: 189 words \\ Total: 1298 words
}

\section{The evolution of music: one trait, many ultimate-level explanations}

Edgar Dubourg, ENS-PSL

edgar.dubourg@gmail.com

0632433751

Jean-Baptiste André, ENS-PSL, CNRS, EHESS

jeanbaptisteandre@gmail.com

\author{
Nicolas Baumard, ENS-PSL, CNRS, EHESS \\ nbaumard@gmail.com
}

\begin{abstract}
We propose an approach reconciling the ultimate-level explanations proposed by Savage et al. and Mehr et al. as to why music evolved. We also question the current adaptationist view of culture, which too often fails to disentangle distinct fitness benefits.
\end{abstract}

\section{Comment:}

Savage et al. focuses on the social functions of music-related behaviors, but they don't explain why musicality, and not music is often preferred to other things like food, perfume and painting, to increase social bonding in humans. Likewise, Mehr's article focuses on the adaptive nature of musicality, which might well be rooted in credible signaling for coalition strength, but they don't expand on how and why music develops new social functions beyond coalition signaling. We argue that both hypotheses need each other to provide a comprehensive and consistent evolutionary understanding of music. We aim at showing why this is the case by disentangling three evolutionary steps.

The first step should account for the fitness benefits of producing music-like sounds in the first place. Mehr et al. provide evidence that contact calls and territorial advertisements may have been the evolutionary precursors of music-related cognitive processes and behavior in humans. Coordinated rhythm, according to Mehr et al., enhanced fitness in local environments when humans evolved because it credibly signaled high level of interindividual coordination. Their hypothesis is seducing because it explains both how music could emerge by natural selection (because it provides a unique way to signal coalition that food or smell cannot provide) and the cognitive constraints such an evolution would have put on all future music-related inventions (they need a least some rhythm). This hypothesis explains why humans evolved cognitive mechanisms to detect and enjoy music-like inputs, at the proximate level. However, it doesn't explain why music evolved culturally with much variability and extend beyond situations of coalitional signaling.

This is the second step. In many species, once a behavioral or phenotypic trait has emerged, it can be co-opted for new adaptive functions. This is very often the case, in particular for traits involved in signaling, as signaling evolves by recycling traits that have first evolved for other 
functions (Krebs \& Dawkins, 1978; Lorenz, 1966). For instance, the female frog Physalaemus pustulosus had pre-existing preferences for lower-frequency chuck sounds, and then males evolved the ability to produce such sounds to exploit this sensory preference (Ryan et al., 1990). In nonhuman animals, this recycling usually emerges by natural selection.

But it can also emerge by cultural evolution. Humans are very plastic. Thanks to their cognitive flexibility, they can recycle existing behaviors and preferences and use evolved preferences (e.g., for sugar, sex, social information, musicality) to shape sophisticated cultural things (e.g., cheesecakes, pornography, stories, music) that other people enjoy consuming. As many have noted, musicians, singers and dancers honestly signal skills and qualities through their performances and this leads to sexual, reputational or material benefits (André et al., 2020; Miller, 2001). Even in modern industrialized societies, musicians and singers take advantage of their productions with economic benefits. We suggest this underlies the producers' motivation to craft such cultural items in the first place.

This second step crucially explains why music appeared in human culture: because (1) humans had evolved a preference for music-like sounds and (2) people adaptively used this preference to do other things. However, it does not explain why, according to many empirical studies reported by Savage et al., music promotes social bonding.

The third step implies that signaling is not necessarily selfish. At least in small-scale societies, consumers should have fitness benefits too. The most obvious one is the acquisition of the information about the musicians, inferred from their music. A similar phenomenon is well described in the non-human animal literature: peacocks impress peahens with their large and beautiful tails, but the peahens are adaptively drawn to them because the size of the tails honestly signal the genetic quality of the peacocks, leading to a more informative sexual partner choice (Petrie, 1994; Petrie et al., 1991; Zahavi, 1975). Likewise, in small scale societies, consumers know how skilled producers of music are merely by listening to their music, and they can arguably better choose skilled cooperative agents or mating partners. In large-scale societies, consumers can take advantage of the fact that other people are also attracted by music to signal preferences, skills and qualities of their own to other people (Bourdieu, 1979; Veblen, 1899).

But there is another social use of music that relates to the first adaptive function of musicality. Coordinated rhythm evolved to be perceived as a credible signal of coalitional bond. Thus, when we listen to coordinated rhythm outside an agonistic context, we cannot help but analyze this signal as a cue that, somehow, we are part of a well-coordinated coalition. Hence, we feel the pleasure of having social support. This would explain why, by default, music makes people cheerful: it mimics the signal that we have coalitional allies (exactly like pornography is arousing because it mimics the signal that we have an opportunity to reproduce). Humans will thus use music in all cases when they need to artificially create social bonding, with actual fitness consequences (Table 1). We propose that most of the findings reported by Savage et al. are best understood in the light of this adaptive recycling.

\section{Effect on recipients}

Positive Negative




\begin{tabular}{|c|c|c|c|}
\hline \multirow[t]{2}{*}{ Effect on actor } & Positive & $\begin{array}{l}\text { Mutualism } \\
\text { - producing artificial signal of } \\
\text { coordination to send and receive } \\
\text { signals of personal quality } \\
\text { - producing artificial signals of } \\
\text { coordination to create bonding for } \\
\text { mutual benefit (e.g., sport) }\end{array}$ & $\begin{array}{l}\text { Selfishness } \\
\text { - producing artificial signal of } \\
\text { coordination to send and receive } \\
\text { false signals of personal quality } \\
\text { - producing artificial signals of } \\
\text { coordination to create bonding for } \\
\text { manipulation (e.g., supermarket) }\end{array}$ \\
\hline & Negative & $\begin{array}{l}\text { Altruism } \\
\text { - producing artificial signals of } \\
\text { coordination in the form of lullabies } \\
\text { to provide social support to children }\end{array}$ & Spite \\
\hline
\end{tabular}

Table 1: Fitness costs and benefits of music-related behavior on both producers and consumers of music, with the framework from social evolution theory (André et al., 2020; Hamilton, 1964).

In sum, we believe evolutionary approaches of cultural items such as music should carefully distinguish fitness costs and benefits from separate evolutionary steps. In that sense, we believe that the publication of these two articles as a pair is an exciting event in the field, if we prevent ourselves from setting them against each other.

\section{Conflicts of interest: none.}

Funding statement: FrontCog ANR-17-EURE-0017

\section{References:}

André, J.-B., Baumard, N., \& Boyer, P. (2020). The Mystery of Symbolic Culture: What fitness costs? What fitness benefits? 18. https://osf.io/kdh7t/download?format $=\mathrm{pdf}$

Bourdieu, P. (1979). La distinction: Critique sociale du jugement. Éditions de Minuit.

Krebs, J. R., \& Dawkins, R. (1978). Animal signals: Mind reading and manipulation. In Behavioral Ecology: An Evolutionary Approach (Blackweel Scientific Publications).

Lorenz, K. Z. (1966). Evolution of Ritualization in the Biological and Cultural Spheres. Philosophical Transactions of the Royal Society of London. Series B, Biological Sciences, 251(772,), 273-284.

Petrie, M. (1994). Improved growth and survival of offspring of peacocks with more elaborate trains. Nature, 371(6498), 598-599. https://doi.org/10.1038/371598a0

Petrie, M., Tim, H., \& Carolyn, S. (1991). Peahens prefer peacocks with elaborate trains. Animal Behaviour, 41(2), 323-331. https://doi.org/10.1016/S0003-3472(05)80484-1

Pinker, S. (1997). How the mind works (Norton pbk). Norton.

Ryan, M. J., Fox, J. H., Wilczynski, W., \& Rand, A. S. (1990). Sexual selection for sensory exploitation in the frog Physalaemus pustulosus. Nature, 343(6253), 66-67.

https://doi.org/10.1038/343066a0

Veblen, T. (1899). Theory of the leisure class (New ed).

Zahavi, A. (1975). Mate selection-A selection for a handicap. Journal of Theoretical Biology, 53(1), 205-214. https://doi.org/10.1016/0022-5193(75)90111-3 